Revista de

Contabilidade e

Organizações
DOI: http://dx.doi.org/10.11606/rco.v11i29.127592
Journal of

Accounting and

Organizations

www.rco.usp.br

\title{
Um estudo das estratégias de internacionalização das indústrias farmacêuticas brasileiras
}

Antonio José Patrocinio Pereira ${ }^{\mathrm{a}}$; Josir Simeone Gomes ${ }^{\mathrm{a}}$

${ }^{a}$ Universidade do Grande Rio

\section{Informações do Artigo}

Histórico do Artigo

Recebido: 06 de março de 2017

Aceito: 23 de maio de 2017

Palavras-chave:

Estratégias de internacionalização.

Indústria farmacêutica.

Laboratórios Nacionais.

\begin{abstract}
Resumo
Esta pesquisa objetiva analisar as estratégias de internacionalização utilizadas por quatro indústrias farmacêuticas brasileiras. A metodologia se caracteriza como descritiva, documental e qualitativa. As indústrias farmacêuticas brasileiras pesquisadas, são classificadas como multinacionais, apresentam tipologias diferenciadas para os modos de entrada no mercado estrangeiro: Eurofarma, EMS e Cristália, por exportação direta, e no caso do Biolab, por via contratual. As estratégias adotadas por essas empresas estudadas, aproximam-se das estratégias de internacionalização mais utilizadas, ao longo das últimas décadas, e são divididas sob dois enfoques: o modelo econômico do paradigma eclético, desenvolvido por Dunning, e o modelo comportamental da Escola de Uppsala, cujos estudos foram conduzidos por Johanson e Vahlne. Os resultados sugerem que as estratégias de internacionalização das organizações estudadas não envolveram, necessariamente, uma ampla sofisticação, pois estão seguindo basicamente o que recomenda a literatura.
\end{abstract}

Copyright (C) 2017 FEA-RP/USP. Todos os direitos reservados

\section{INTRODUÇÃO}

As organizações brasileiras ainda dão pouco foco à exploração em países estrangeiros. Entretanto, devido à atual crise brasileira, a quantidade de empresas que estão se internacionalizando pela primeira vez os estreantes do mercado externo, em 2016 aumentou 149\% em relação a 2015, conforme informações do Ministério da Indústria, Comércio Exterior e Serviços [MDIC] (2017).

Segundo os dados da IMS Health (2017), empresa que audita o mercado farmacêutico mundial, as vendas deste setor fecharam em 2015 em torno de US\$ 1.068,8 bilhões. Os Estados Unidos, a Europa Ocidental e o Japão, em 2014, detiveram cerca $70 \%$ das vendas e as vinte maiores empresas, chamadas de "big pharmas", em torno de $60 \%$ do mercado internacional. O órgão projeta que o Brasil, que ocupava o $10^{\circ}$ lugar no mercado farmacêutico mundial em 2010, terá o $5^{\circ}$ maior mercado em 2020.

As vendas das empresas farmacêuticas brasileiras apresentaram um crescimento nominal, em 2016, de $12,6 \%$ e, nos últimos seis anos, uma média de 16,7\% ao ano. Nos últimos dois anos a indústria farmacêutica fechou com uma taxa real de $6,53 \%$, enquanto o PIB brasileiro fechou negativo em $8 \%$ no mesmo período, segundo o Sindicato da Indústria de Produtos Farmacêuticos no Estado de São Paulo [SINDUSFARMA] (2017). Por outro lado, de acordo com Banco Central do Brasil [BACEN] (2017), o cenário industrial sofreu uma queda de $16 \%$. Estatisticamente, observa-se as que as empresas farmacêuticas apresentam taxas positivas, muito acima dos demais parques industriais.

No Brasil, o processo de internacionalização iniciou-se com as exportações de produtos farmacêuticos para América Latina, no período de 2009 a 2013, representando mais de 50\% das vendas, e apresentando vantagens competitivas com relação à escala e à qualidade sanitária, conforme Gomes, Pimentel, Cardoso e Pieroni (2014). Os principais fatores que influenciam o crescimento da demanda por produtos farmacêuticos no Brasil, são: o envelhecimento da população; o maior uso de medicamentos genéricos; a melhoria do nível médio de renda

Autor Correspondente: Tel (21) 3219-4040

E-mail: patrocinioajp@gmail.com (A. J. P. Pereira); josirsgomes@gmail.com (J. S. Gomes)

UNIGRANRIO - Rua Professor José de Souza Herdy, 1160 - Jardim Vinte e Cinco de Agosto, Duque de Caxias - RJ, 25070-000, Brasil. 
e os subsídios concedidos, pelo governo federal, a consumidores de baixa renda, como o Programa Farmácia Popular, segundo a IMS Health (2017). Por outro lado, o consumo de medicamentos genéricos e similares (medicamentos cuja patentes já expiraram) são 60\% em média mais baratos que os produtos de marca ou de referência (medicamentos inovadores).

O mercado brasileiro de medicamentos genéricos detém apenas 31,40 \% das vendas em unidades, em relação ao mercado farmacêutico total. Segundo a Associação Brasileira das Indústrias de Medicamentos Genéricos [PróGenéricos] (2017), a meta é atingir de 35\% a 40\% em 2020, muito aquém de países da Europa (50\%), Canadá (50\%) e dos Estados Unidos, onde os genéricos têm mais de 20 anos de existência, e a participação de aproximadamente $80 \%$ em volume.

Variadas pesquisas, direcionadas à produção científica sobre o tema internacionalização, foram divulgadas em periódicos nacionais e internacionais. Em estudos recentes, os autores Ferreira, Cavalcanti e Gomes (2014) identificaram 174 artigos publicados na biblioteca eletrônica de periódicos científicos (SPELL), no período 20092013. Dentro dessa temática, no período de 2010 a 2012, houve uma evolução em relação ao número de artigos publicados sobre as teorias já consolidadas, tanto na perspectiva econômica como na comportamental, abordadas neste estudo. Entretanto, ainda existe uma lacuna sobre estudos nesta área e voltados para o mercado farmacêutico.

Dessa forma, este artigo tem como questão de pesquisa: Quais as estratégias adotadas pelas empresas farmacêuticas Eurofarma, EMS, Cristália e Biolab, que passaram ao largo da atual crise econômica brasileira? Para responder a este questionamento tem-se como objetivo analisar as estratégias adotadas por essas empresas farmacêuticas, que surgiram, principalmente, na década de 1990, logo após a lei dos genéricos, com a finalidade de se transformarem em fortes competidoras no mercado doméstico face à internacionalização.

Diante disso, a metodologia da pesquisa adotada é descritiva, documental e qualitativa e selecionamos as quatro principais indústrias farmacêuticas brasileiras internacionalizadas. O referencial teórico utilizado no estudo, foram as estratégias de internacionalização mais utilizadas, ao longo das últimas décadas, as vertentes econômicas e as comportamentais. Os resultados obtidos indicam uma aproximação com os modelos tradicionais de estratégias de internacionalização, gerando um aprendizado organizacional a essas empresas, o que lhes tem permitido se manter competitivas a fim de enfrentar esses novos desafios, apesar da atual crise econômica e política.

\section{REFERENCIAL TEÓRICO}

No referencial teórico deste estudo é apresentado o processo de internacionalização de empresas e as teorias sobre um enfoque econômico e comportamental, que são retratadas através de um quadro-resumo.

\subsection{O processo de internacionalização de empresas}

A internacionalização é a denominação de um processo de elaboração e implantação do planejamento estratégico das empresas, de forma a operarem em países diferentes daquele no qual está originalmente instalada, conforme Barreto (2002). Esse processo pode ser considerado uma estratégia que acelera as atividades econômicas de organizações com mercados internacionais, num sentido próximo ao apresentado por Ruzzier, Hisrich e Antoncic (2006) e Souza e Fenili (2012).

Normalmente as empresas internacionalizadas são classificadas, conforme Bartlett e Ghoshal (1992), Canals (1994) e Dyment (1987) da seguinte forma: no país sede;

a) Empresa exportadora - é o começo do processo de internacionalização, as fábricas ficam geralmente,

b) Empresa multinacional - a finalidade dessas organizações é a fabricação similar das atividades de sua matriz em cada uma das filiais em países estrangeiros;

c) Empresa global - tem um sistema centralizado de produção de mercadorias que é instalado num determinado país e somente comercializa a produção para outros;

d) Empresa transnacional - procura ser eficiente para obter uma competitividade global. 
Além da classificação de empresas internacionalizadas verificam-se na literatura diversas pesquisas que apresentam tipologias diferenciadas para os modos de entrada, no mercado externo. Sarathy e Terpstra (1991), Cateora e Graham (1996) e Brito e Lorga (1999), conceituam assim as formas mais utilizadas:

a) Exportação direta: produz e exporta diretamente os seus produtos ao consumidor final no estrangeiro;

b) Exportação indireta: empresas brasileiras, que compram os produtos para comercializar no exterior, geralmente através de agentes, representantes e distribuidores (trading companies);

c) Acordo de distribuição: acordo assinado entre o exportador e um distribuidor legalmente constituído com conhecimento técnico de seus produtos para mercado externo;

d) Licenciamento/franquia: a empresa licenciadora autoriza, através de um contrato, a empresa licenciada na produção e/ou na comercialização de seus produtos, não alterando as características originais de marca, modelo e layout, etc. contra um pagamento, chamado de royalties;

e) Subsidiária de vendas: através de um escritório de vendas, a empresa produtora fixa a sua presença física no estrangeiro;

f) Centro de distribuição próprio: a exportadora dissemina a sua produção no estrangeiro. O ônus financeiro é maior, comparando-se com a implantação de uma subsidiária de vendas;

g) Alianças estratégicas e joint-ventures: espécie de consórcio ou acordo de colaboração entre as organizações do local e do exterior que admitem partilhar os riscos, gastos e valores, etc.;

h) Fusão: união de duas ou mais empresas do mesmo ramo ou complementares, cuja estratégia é aumentar a participação, no mercado ou valer-se dessa cooperação;

i) Aquisição: uma organização compra o controle acionário de outra que já está estabelecida no país e somente uma delas manterá a sua identidade;

j) Greenfield: montagem de uma subsidiária, começando do zero. Esse capital investido traduz-se do inglês como "campo verde".

Diante do que foi conceituado, Root (1994) apresenta um sumário em 3 tipologias diferenciadas para os modos de entrada no mercado estrangeiro: 1) por exportações (exportação direta e indireta); 2) contratuais (licenciamento, franquia, acordos e contratos); e 3) investimentos (novos empreendimentos, aquisições e joint ventures).

\subsection{Enfoque econômico}

Este enfoque tende a interpretar processos decisórios de internacionalização como lógicos e materiais, com foco na distribuição certa de recursos, reduzindo custos totais associados a uma transação, com vantagem competitiva. Inserem-se, nesta vertente: a teoria do poder de mercado; a teoria do ciclo do produto, a teoria da internalização e o paradigma eclético.

A teoria do poder de mercado, do economista Hymer S. (1960), considerado seu principal representante, se fixa em reconhecer que o Investimento Direto no Exterior (IDE) é mais perceptível em empresas industriais.

Na teoria do ciclo do produto, o principal representante é o contemporâneo de Hymer, Raymond Vernon (1931-1999). Para Vernon (1966), empresas que enfrentassem fases de maturidades em mercados locais deveriam aumentar o ciclo de vida dos seus produtos, entrando em mercados, cujo nível de desenvolvimento estivesse numa fase inicial, retirando vantagens comparativas das, já comprovadas, novidades dos seus produtos.

Para a Teoria da Internalização, que tem como principais autores Buckley e Casson (1976), apoiados nos conceitos da Teoria dos Custos de Transação de Williamson (1985), atribui-se importância ao conceito de internalização para justificar a existência dos processos de internacionalização.

Partindo dos princípios da economia, do conceito de custo de transação e da Teoria da Internalização, passa existir o do paradigma eclético. Dunning (1998), seu desenvolvedor, reconheceu que não é uma teoria nova, mas que procura explicar o processo de internacionalização das empresas.

A propriedade, a internacionalização e a localização, seriam os três elementos relevantes em cada tomada de decisão pelas organizações que operam por meio da produção nos mercados internacionais. A Teoria do 
Paradigma Eclético ou Teoria OLI, propõe explicar a amplitude, a forma e o padrão da produção internacional com base em três grupos de vantagens: 1) Ownership (O) - vantagens de propriedade de ativos específicos da empresa; 2) Location (L) - vantagens que o meio ambiente provoca nas competências da empresa, 3) Internalization (I) - vantagens que decorrem de a empresa garantir as atividades, num outro país, através dos seus próprios meios.

De acordo com Souza e Fenili (2012), o paradigma eclético é um “arcabouço analítico amplo”, capaz de abarcar as deficiências de mercado causadas pelo desenvolvimento da empresa em seu mercado doméstico (teoria do poder de mercado), o fato de as empresas se internacionalizarem com foco no aproveitamento das deficiências de mercados estrangeiros (teoria da internalização).

Contextualizando, o paradigma eclético elucida quando uma firma procura iniciar uma produção internacional e pode ter alguma vantagem competitiva. Dado isso, a firma se internacionalizá, realizará IDE - se considerar que essa é a melhor decisão a ser tomada e havendo interesse econômico (lucro) em realizar a produção no exterior.

\subsection{Enfoque comportamental}

Enquanto no enfoque econômico as Teorias da Internacionalização foram desenvolvidas com um olhar macro, um enfoque alternativo foi dado no âmbito da administração, ao propor explicações sobre o processo pelo qual uma empresa ingressa no mercado internacional e sobre a influência das atitudes, percepções e expectativas dos seus executivos (conhecido como enfoque comportamental ou processual), segundo Barreto (2002). Este enfoque apresenta maior subjetividade, admitindo uma visão comportamental, observando a internacionalização, a partir das posturas e da perspicácia dos tomadores de decisão das empresas. Inserem-se, nesta perspectiva, a teoria da Escola de Uppsala (ou simplesmente modelo de Uppsala) e a da Escola Nórdica de Negócios Internacionais, resumidas a seguir.

A teoria da escola de Uppsala cujo enfoque foi desenvolvido por pesquisadores suecos, na década de 1970 e oriunda dos estudiosos da Escola Nórdica deu ênfase aos estudos conduzidos por Johanson e Vahlne (1977), Johanson e Wiedersheim-Paul (1975), que defendem a tese de que uma organização que passa por fases e modelos, contém dados com adequações e aumentos proporcionais. A organização desses dados leva a diversas operações entre elas a seleção do mercado-alvo maneiras de entrar no mercado internacional e situações que irão encontrar.

Deste modo, uma organização inicia a exportação para um determinado país através de representantes, depois estabelece uma subsidiária de vendas e, por fim, principia a produção efetiva para aquele país escolhido. Para este modelo, "a internacionalização é um processo de ajustes incrementais às condições variáveis da empresa e do seu ambiente, apresentando os seguintes estágios de envolvimento internacional" (Rodrigues \& Gomes, 2003):

Estágio 1 - não existência de atividades regulares de exportação;

Estágio 2 - exportação feita através de representantes independentes;

Estágio 3 - estabelecimento de uma subsidiária de venda no exterior;

Estágio 4 - unidades de operações no exterior (produção, por exemplo).

Para Johanson e Vahlne (2009), "essa sequência de estágios indica o comprometimento crescente de recursos com o mercado. Ela indica, ainda, as atividades correntes (operações) que se diferenciam em razão da experiência acumulada".

A teoria ou modelo da Escola Uppsala, aponta característica relevante na percepção da distância psíquica ou psicológica entre o país de origem e os países estrangeiros no processo de internacionalização da firma, segundo Hemais e Hilial (2004). Esta distância pode ser definida como as diferenças percebidas entre valores, idiomas, práticas ou controles gerenciais, desenvolvimento industrial e educação de dois países, ou seja, as empresas realizam negócios com países culturalmente mais próximos. Uma distância cultural muito grande, seguindo esta concepção, inviabilizaria a realização de negócios internacionais.

$\mathrm{Na}$ teoria Uppsala, a perspectiva do processo de internacionalização foi revisitada em especial pela complexidade do mercado, antes desconhecida. Ao contrário, seria orientada por uma natureza do que seja incremental para a firma que visa a uma aprendizagem por meio do comprometimento crescente com os mercados estrangeiros. Seria possível, portanto, acelerar o processo e entrar diretamente em mercados psiquicamente distantes, conforme Johanson e Vahlne (1977). 
A partir da teoria Uppsala, surge a Teoria Comportamental da Escola Nórdica de Negócios Internacionais, atrelada às redes de relacionamentos (networks), e que, segundo Hemais e Hilial (2004), pode ser considerada uma evolução natural do pensamento dessa escola. Em relação às novas tendências em estudos de negócios internacionais, Andersson (2000) é um dos principais representantes dessa teoria comportamental da Escola Nórdica e ele aponta o empreendedorismo como relevante nesse processo.

Com finalidade de dar uma visão mais global das principais teorias da internacionalização, apresentase, a seguir, um quadro-resumo elaborado por Hemais e Hilial (2004), focando os principais autores e pontos defendidos das duas perspectivas ou enfoques: um sobre uma vertente econômica e outro sobre uma vertente organizacional ou comportamental.

\begin{tabular}{|c|c|c|c|c|}
\hline Enfoque & Teoria & $\begin{array}{c}\text { Principal } \\
\text { Autor }\end{array}$ & Ideia básica & Força motora \\
\hline \multirow{4}{*}{ Econômico } & $\begin{array}{l}\text { Poder de } \\
\text { Mercado }\end{array}$ & S.Hymer & $\begin{array}{l}\text { Firmas operam no exterior } \\
\text { para controlar outras } \\
\text { empresas e usar suas } \\
\text { vantagens competitivas. }\end{array}$ & $\begin{array}{l}\text { Alargamento das collusive networks } \\
\text { e restrições à concorrência em cada } \\
\text { mercado. }\end{array}$ \\
\hline & $\begin{array}{l}\text { Ciclo do } \\
\text { Produto }\end{array}$ & R.Vernon & $\begin{array}{l}\text { Firmas inovam em seus } \\
\text { mercados locais e transferem } \\
\text { a produção de produtos } \\
\text { menos sofisticados para } \\
\text { países em desenvolvimento, } \\
\text { isto é, produtos maduros são } \\
\text { produzidos em países em } \\
\text { desenvolvimento. }\end{array}$ & $\begin{array}{l}\text { Procurar locações que apresentem } \\
\text { menores custos para tecnologias } \\
\text { estáveis. }\end{array}$ \\
\hline & Internalização & $\begin{array}{l}\text { P.Buckley } \\
\qquad \& \\
\text { M.Casson }\end{array}$ & $\begin{array}{l}\text { Firmas internalizam } \\
\text { mercados quando custos } \\
\text { de transação de uma troca } \\
\text { administrativa são menores } \\
\text { que os custos de mercado; } \\
\text { assim, aumenta a eficiência } \\
\text { coletiva do grupo. }\end{array}$ & $\begin{array}{l}\text { A expansão ou contratação da } \\
\text { produção internacional depende de } \\
\text { mudanças nos custos das transações } \\
\text { de operar em um conjunto maior } \\
\text { de mercados, comparados com o } \\
\text { custo de coordenar diretamente as } \\
\text { transações. }\end{array}$ \\
\hline & $\begin{array}{l}\text { Paradigma } \\
\text { eclético }\end{array}$ & J. Dunning & $\begin{array}{l}\text { Firmas operam no exterior } \\
\text { quando têm vantagens } \\
\text { competitivas em propriedade } \\
\text { (O), Localização (L) e } \\
\text { Internalização (I). }\end{array}$ & $\begin{array}{l}\text { Uso da OLI no processo de } \\
\text { internacionalização da empresa. }\end{array}$ \\
\hline $\begin{array}{l}\text { Comportamental } \\
\text { ou }\end{array}$ & $\begin{array}{l}\text { Escola de } \\
\text { Uppsala }\end{array}$ & $\begin{array}{l}\text { J. Johanson } \\
\text { \& J.E.Vahlne }\end{array}$ & $\begin{array}{l}\text { Distância psíquica, } \\
\text { internacionalização } \\
\text { incremental e networks. }\end{array}$ & $\begin{array}{l}\text { Envolvimento crescente da firma a } \\
\text { partir do aumento do conhecimento } \\
\text { sobre a nova localização. }\end{array}$ \\
\hline Organizacional & $\begin{array}{l}\text { Escola } \\
\text { Nórdica }\end{array}$ & Andesson.S & Empreendedorismo & $\begin{array}{l}\text { Papel do empreendedor como } \\
\text { fundamental no processo de } \\
\text { internacionalização da firma. }\end{array}$ \\
\hline
\end{tabular}

Quadro 1. Resumo das principais teorias da Internacionalização.

Fonte: Hemais e Hilal (2004, p. 36).

No Quadro 1, pode-se observar que as teorias são mais complementares do que contrárias. O processo de internacionalização da firma não é simples de se compreender e uma teoria não seria capaz de encontrar explicação suficiente que esclarecesse totalmente o fenômeno. 


\section{METODOLOGIA}

\subsection{Enquadramento metodológico}

Ao ingressar no campo da pesquisa científica, verifica-se que há várias classificações de tipologias aplicáveis por diversos autores, bem como os resultados delas decorrentes. Vergara (2016) propõe dois critérios básicos: quanto aos fins exploratória, descritiva, explicativa, metodológica, aplicada, intervencionista e quanto aos meios: pesquisa de campo, pesquisa de laboratório, documental, bibliográfica, experimental, ex pos facto, participante, pesquisa-ação e estudo de caso.

$\mathrm{Na}$ busca de respostas para o problema da pesquisa, a metodologia da pesquisa adotada é descritiva quanto aos seus fins, pois se preocupa em observar os fatos, registrá-los, analisá-los, classificá-los e interpretá-los sem a interferência dos pesquisadores, ou seja, os fenômenos do mundo físico e humano são estudados, mas não manipulados pelo pesquisador. A pesquisa desenvolveu-se em um estudo sistemático bibliográfico e documental quanto aos meios. Utilizou-se de material publicado em livros, revistas, jornais, redes eletrônicas como fontes foram primárias e secundárias, além da utilização de documentos internos da organização que foram encaminhados por meios eletrônicos.

Finalizando as tipologias aplicadas ao trabalho a pesquisa pode ser considerada predominantemente qualitativa quanto a sua abordagem, uma vez que se caracteriza pela não a utilização de instrumentos estatísticos. Richardson (1999) define a pesquisa qualitativa como estudos que procuram descrever a complexidade de determinado problema, analisar a interação de certas variáveis e compreender e classificar processos dinâmicos vividos por grupos sociais. Na Contabilidade e na Administração, é bastante comum o uso da abordagem qualitativa. Cabe aqui ressaltar que, embora ambas as ciências lidem com números, elas são uma ciência social, e não uma ciência lógica, o que justifica a relevância do uso da abordagem qualitativa.

\subsection{Coleta de dados}

Para fins de se adequar ao tema, a escolha do critério e requisitos de seleção baseou-se em uma amostra intencional do segmento farmacêutico, dentro do grupo das empresas responsáveis pela produção e comercialização de medicamentos genéricos e similares, considerando os seguintes fatores para análise de estudo: a) O controle acionário ser nacional; b) pertencer ao setor industrial; c) interesse pela internacionalização; d) serem de grande porte.

A coleta dos dados constantes nos quadros 2 e 3 do estudo, foram obtidas com base em material publicado nos sites das empresas analisadas, press-releases, vídeo institucional, revista Exame "Melhores e Maiores" julho de 2016, revista Valor Econômico "1000 Maiores Empresas" de setembro de 2016, revista Valor "Inovação Brasil" de julho 2016, Revista Folha de São Paulo de 29 de julho de 2016, relatório anual de 2016 encaminhado pelo Laboratório Eurofarma, relatórios financeiros afixados no próprio site dos laboratórios e informações coletadas nos sites do Banco Nacional Desenvolvimento Social [BNDES] (2017) e do Serviço Brasileiro de Apoio às Micro e Pequenas Empresas [SEBRAE] (2017).

\section{DESCRIÇÃO E ANÁLISE DE RESULTADOS}

\subsection{Descrição das indústrias analisadas}

As organizações, objetos de análise desse estudo, foram escolhidas mediante um leque de opções sendo que os Laboratórios Eurofarma, EMS, Cristália e Biolab, se destacaram do conjunto, nos quesitos diferenciados de metodologia de entrada no mercado internacional. A seguir, um breve histórico do portfólio dos laboratórios em destaque. As informações foram coletadas, nos seus respectivos sites. 


\subsubsection{Cenário institucional dos laboratórios farmacêuticos pesquisados}

Fundada em 1972, com capital $100 \%$ nacional, a Eurofarma aderiu às exportações de seus produtos em 2002; portanto, permaneceu por 30 anos longe dos avanços comerciais em mercados estrangeiros. Porém, a partir desta data esteve alinhada à sua meta de cobrir 90\% da demanda para os países latino-americanos até 2015 . Em 2009, a empresa adquiriu o laboratório argentino Quesada e entre 2010 a 2014, continuou suas aquisições de mais cinco laboratórios nos demais países da América Latina. Com isso, a organização passou a cobrir $68,6 \%$ do mercado latino-americano, de acordo com as informações contidas no site do Laboratório Eurofarma (2017).

Com base no balanço de 31 de dezembro de 2015, o valor das vendas líquidas da Eurofarma foi de 2.164,4 milhões de reais, o equivalente a 554,3 milhões de dólares. A empresa ocupa o $7^{\circ}$ lugar no ranking entre as maiores, classificadas por vendas líquidas em milhões de dólares, conforme a revista Exame "Melhores \& Maiores 2016".

O Laboratório EMS, segundo informações constantes no site, tem o capital 100\% nacional, com início das atividades em 1964. No ano 2000, 36 anos após sua fundação, começou o seu processo de internacionalização, com exportações para outros países da América Latina, além da Europa, África, Ásia e Oriente Médio; atualmente, está presente em mais de 40 países. Em 2013, nos Estados Unidos foi instalada a empresa Brace Pharma no Estado de Maryland, totalmente voltada à inovação radical. Conta com 5 mil colaboradores em todo Brasil. Segundo a revista Exame "Melhores \& Maiores 2016", o valor das vendas líquidas foi de 2.211,3 milhões de reais, equivalentes a 566,3 milhões de dólares, e ocupa o $6^{\circ}$ lugar no ranking entre as maiores, classificadas por vendas líquidas em milhões de dólares.

O Laboratório Cristália, de acordo com as informações coletadas no site da empresa (2017) iniciou as suas operações em 1972, a partir de um pequeno laboratório para suprimir a demanda de medicamentos psiquiátricos. Exporta tanto medicamentos, como IFAs (Insumos Farmacêuticos Ativos) para mais de 30 países da América Latina, África e Oriente Médio, com 300 registros no exterior. Atualmente conta com cerca de 5.200 colaboradores (Laboratório e coligadas). O valor das vendas líquidas foi de 1.427,6 milhões de reais, o equivalente a 365,6 milhões de dólares, com base no balanço de 31 de dezembro de 2015, ocupando o $9^{\circ}$ lugar no ranking entre as maiores, classificadas por vendas líquidas em milhões de dólares, conforme a revista Exame "Melhores \& Maiores $2016 "$.

A empresa Biolab iniciou suas atividades em 1997, com foco em medicamentos inovadores, responsáveis por mais de $50 \%$ do seu faturamento e investe $10 \%$ em pesquisa, desenvolvimento e inovação. Atualmente, conta com mais de 2 mil funcionários e visita mensalmente, 250 mil médicos em todo o território brasileiro, assegurando à classe médica uma presença amiga, além de atualização constante e opções inovadoras, conforme informações constantes no site do Laboratório (2017).

\subsection{Análise dos resultados}

A fim de organizar o estudo, os laboratórios foram estruturados de forma descritiva, a partir das informações obtidas na coleta de dados, resumidos nos quadros 2 e 3. No Quadro 2, resumo dos dados, temos que Eurofarma, EMS e Cristália atuam, no mercado farmacêutico, há pelo menos quarenta anos, a exceção é do Biolab, considerado jovem no grupo analisado. Todos são considerados de grande porte, tanto no que tange ao seu faturamento quanto ao número de funcionários. Todos têm como atividade principal a indústria farmacêutica, apresentam o capital fechado, e controle acionário 100\% brasileiro. Quanto ao tempo de internacionalização, Eurofarma e EMS, atuam neste mercado numa média de 15,5 anos, sendo que o laboratório Eurofarma, iniciou esse processo, com exportações e aquisição de empresas há 7 anos. Já Cristália e Biolab são mais recentes neste processo de internacionalização, com uma média de 4 anos. 


\begin{tabular}{|c|c|c|c|c|}
\hline INDÚSTRIAS & EUROFARMA & EMS & CRISTÁLIA & BIOLAB \\
\hline Porte da Empresa $\left({ }^{1},{ }^{6}\right)$ & Grande Porte & Grande Porte & Grande Porte & Grande Porte \\
\hline $\mathrm{N}^{\circ}$ funcionários & $6.521(2015)^{7}$ & $5.000^{4}$ & $4.000^{4}$ & $2.350^{4}$ \\
\hline Presidente $(C E O)$ & Maurizio Billi & Carlos E.Sanchez & Ogari Pacheco & Cleiton Marques \\
\hline Atividade principal ${ }^{4}$ & $\begin{array}{l}\text { Indústria } \\
\text { farmacêutica }\end{array}$ & $\begin{array}{l}\text { Indústria } \\
\text { farmacêutica }\end{array}$ & $\begin{array}{l}\text { Ind. farmacêutica e } \\
\text { farmoquímica }\end{array}$ & Indústria farmacêutica \\
\hline Tipo de Capital ${ }^{4}$ & Capital Fechado & Capital Fechado & Capital Fechado & Capital Fechado \\
\hline Capital $^{4}$ & $100 \%$ brasileiro & $100 \%$ brasileiro & $100 \%$ brasileiro & $100 \%$ brasileiro \\
\hline $\begin{array}{l}\text { Tempo de Atividade } \\
\text { (Fundação) }{ }^{4}\end{array}$ & $44 \operatorname{anos}(1970)$ & $52 \operatorname{anos}(1964)$ & $44 \operatorname{anos}(1972)$ & 19 anos (1997) \\
\hline $\begin{array}{l}\text { Tempo com } \\
\text { Internacionalização }{ }^{4}\end{array}$ & 14 anos & 17 anos & 6 anos & 2 anos \\
\hline $\begin{array}{l}\text { Início Processo da } \\
\text { Internacionalização }{ }^{4}\end{array}$ & 2002 & 2000 & 2011 & 2015 \\
\hline Foco Principal ${ }^{4}$ & $\begin{array}{l}\text { Prescrição médica e } \\
\text { genéricos. }\end{array}$ & $\begin{array}{l}\text { Prescrição médica e } \\
\text { genéricos. }\end{array}$ & $\begin{array}{l}\text { Diferenciados, } \mathrm{n} / \mathrm{c} \\
\text { genéricos }^{3}\end{array}$ & $\begin{array}{l}\mathrm{n} / \mathrm{c} \text { genéricos, só } \\
\text { inovadores }^{3}\end{array}$ \\
\hline Portfólios Produtos ${ }^{4}$ & 280 medicamentos & 500 medicamentos & 200 medicamentos $^{3}$ & 100 medicamentos \\
\hline $\mathrm{N}^{0}$ Licenças exterior ${ }^{4}$ & $\mathrm{NC}$ & 400 & $300^{5}$ & 220 \\
\hline $\begin{array}{l}\text { Vendas Globais (BR + } \\
\text { Internacional) milhões }{ }^{3}\end{array}$ & $\begin{array}{l}\mathrm{R} \$ 2,164,4 \\
\mathrm{US} \$ 554,3\end{array}$ & $\begin{array}{l}\mathrm{R} \$ 2,211,3 \\
\mathrm{US} \$ 566,3\end{array}$ & $\begin{array}{l}\mathrm{R} \$ 1.427,6 \\
\mathrm{US} \$ 365,6\end{array}$ & $\begin{array}{l}\mathrm{R} \$ 1.350,0 \\
\text { (Projeção 2015) }^{4}\end{array}$ \\
\hline 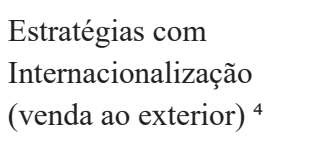 & $\begin{array}{l}10 \%(2014)^{7} \\
13 \%(2015)^{7} \\
\mathrm{NC}(2016)^{7}\end{array}$ & $\mathrm{NC}$ & $\begin{array}{l}6 \%(2014)^{3} \\
10 \%(2015)^{3} \\
15 \%(\text { Meta } 2017)^{3}\end{array}$ & $\mathrm{NC}$ \\
\hline $\begin{array}{l}\text { Investimento P \& D, e } \\
\text { Inovação }\end{array}$ & $\begin{array}{l}5,3 \% \\
\text { Receita Líquida }^{7}\end{array}$ & $\begin{array}{l}6 \% \\
\text { Faturamento }^{3}\end{array}$ & $\begin{array}{l}8 \% \\
\text { Faturamento }^{3}\end{array}$ & $\begin{array}{l}7 \text { a } 10 \% \\
\text { Faturamento } 4\end{array}$ \\
\hline
\end{tabular}

Quadro 2. Resumo de dados coletados das empresas farmacêuticas brasileiras.

Fonte: Os autores.

Notas: ${ }^{1}$ Classificação porte Empresa (BNDES). Receita operacional bruta anual maior que R $\$ 300$ milhões, considerada grande porte. ${ }^{2}$ Fonte Revista Exame "Melhores e Maiores", julho de 2016. As maiores farmacêuticas, classificação venda líquidas, base 2015. ${ }^{3}$ Revista Valor Econômico "1000 maiores empresas" (set-2016); Inovação Brasil (julho - 2016), o TOP 5 do Segmento Farmacêutico. ${ }^{4}$ Site da empresa ou vídeo institucional. ${ }^{5}$ Revista Folha de São Paulo (julho - 2016). "Farmacêuticas brasileiras compram empresas no exterior por inovação". "SEBRAE utiliza o critério por número de empregados do IBGE como critério de classificação do porte das empresas (indústria), considera como grande porte mais de 500 empregados. ${ }^{7}$ Relatório Anual Laboratório Eurofarma (2016). NC - Não consta nos levantamentos coletados.

No Quadro 2 pode-se observar que os Laboratórios Eurofarma e Cristália apresentam metas de estratégias de internacionalização (venda ao exterior), com mais de 10\% sobre a venda total, todavia, sobre o EMS e o Biolab, não constam dados disponíveis. O foco principal desses laboratórios é a venda de medicamentos genéricos e similares; há um percentual importante em investimentos em Pesquisa, Desenvolvimento e Inovação (PD\&I).

Analisando-se o Quadro 3, as estratégias da internacionalização nos remetem aos enfoques apresentados no referencial teórico. No enfoque econômico, a teoria/modelo do paradigma eclético, encontram-se nos quatro laboratórios pesquisados, fundamentados no conceito OLI. 


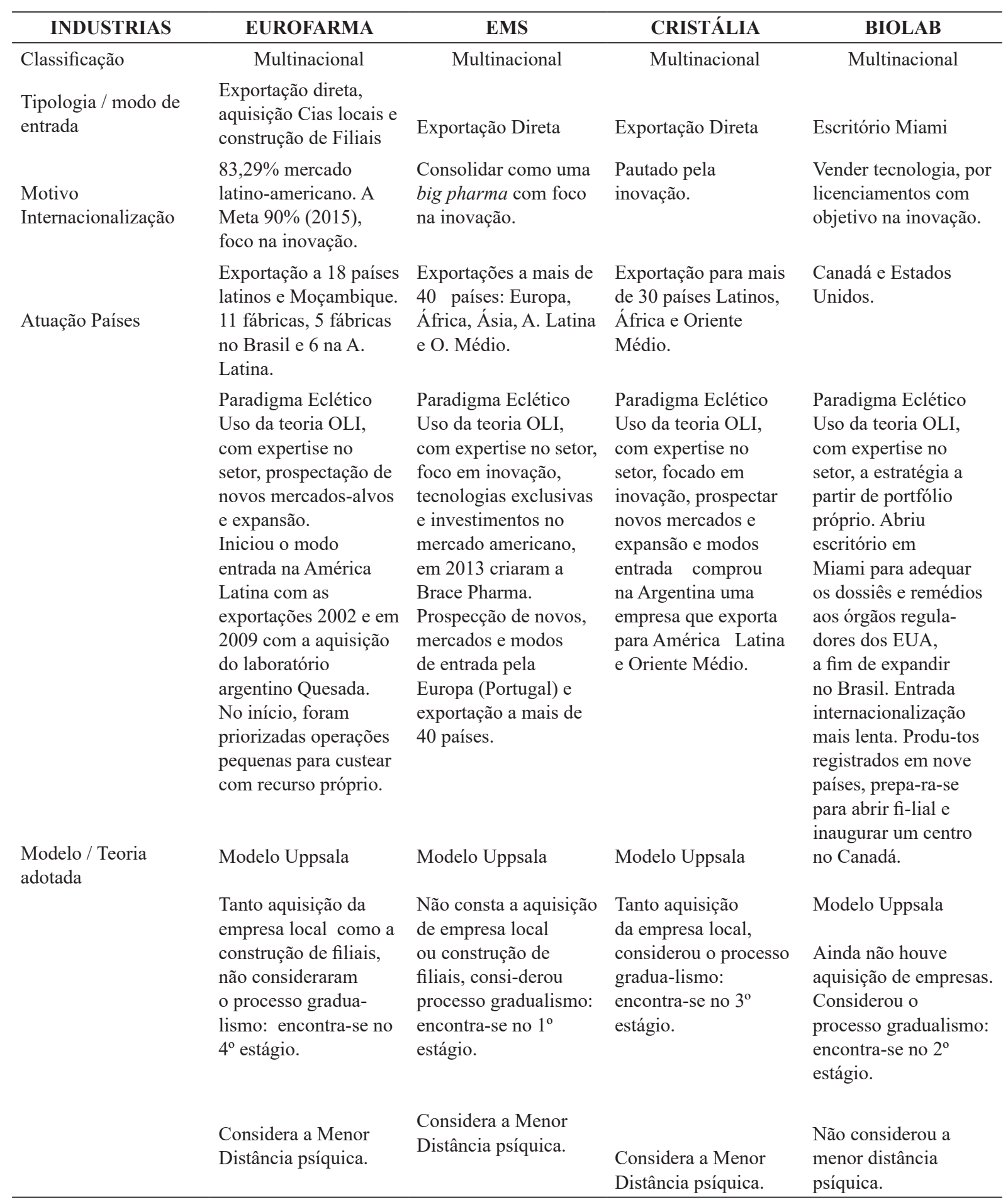

Quadro 3. Processo Internacionalização, Classificação, Tipologia, Motivação e Modelo adotado

Fonte: Os autores, 2017.

Sob o enfoque comportamental, no Quadro 3 verifica-se aplicabilidade da teoria ou Modelo Uppsala, nos quatro laboratórios estudados. Entretanto, na questão ligada à percepção de distância psíquica, o laboratório Biolab, não considerou a menor distância psíquica em relação aos demais. Percebe-se que cada uma das indústrias estudadas apresenta estágios diferentes de internacionalização. O Eurofarma se encontra no $4^{\circ}$ estágio; o EMS no $1^{\circ}$ estágio; o Cristália no $3^{\circ}$ estágio e o laboratório Biolab no $2^{\circ}$ estágio. Nota-se que todas as indústrias adotaram, como modos de entrada, o processo de gradualismo. Fica evidenciado no Quadro 3 que os quatro laboratórios, têm uma motivação em comum, além da internacionalização, a inovação, a fim de aprender e de se apropriar de tecnologias avançadas. 


\section{CONSIDERAÇÕES FINAIS}

Este artigo teve como objetivo analisar e identificar as estratégias de internacionalização utilizadas pelas quatro indústrias farmacêuticas brasileiras com as principais teorias de internacionalização disponíveis na literatura. Observa-se, com a análise dos resultados obtidos, que todas as empresas analisadas são de segmentos industriais semelhantes e são de grande porte, pois se enquadram no critério adotado pelo BNDES e SEBRAE.

Quanto à classificação das indústrias farmacêuticas brasileiras pesquisadas, todas são classificadas como multinacionais, conforme descrito, na literatura, pelos autores Bartlett e Ghoshal (1992), Canals (1994). Dyment (1987). As empresas apresentam tipologias diferenciadas para os modos de entrada no mercado estrangeiro: Eurofarma, o EMS e Cristália, por exportação direta, e Biolab por via contratual, de acordo com Root (1994).

Todos os laboratórios estudados, procurando alguma vantagem competitiva, adotaram estratégias de internacionalização, sob a perspectiva do enfoque econômico, como a teoria do paradigma eclético ou teoria OLI, segundo seu desenvolvedor, John Dunning (1998). Em relação à perspectiva comportamental, cujos estudos foram conduzidos por Johanson e Vahlne (2009), verifica-se que todos os laboratórios analisados se enquadram na teoria da Escola de Uppsala e, encontram-se em estágios distintos de envolvimento internacional. Apenas o laboratório Eurofarma, não considerou o processo gradualismo recomendado pela literatura e o laboratório Biolab não considerou a menor distância psíquica em relação aos demais.

Por fim, pode-se concluir que as estratégias adotadas por essas empresas estudadas se aproximam das estratégias de internacionalização mais utilizadas, ao longo das últimas décadas, que são divididas sob dois enfoques: o modelo econômico do paradigma eclético e o modelo comportamental da Escola de Uppsala. Dessa forma, os resultados sugerem que não se envolve, necessariamente, uma ampla sofisticação no processo de internacionalização nessas indústrias estudadas, pois estão seguindo basicamente o que a literatura recomenda.

Uma ressalva importante diz respeito à possível generalização dos resultados desse estudo, com se trata de uma pesquisa baseada no processo de internacionalização de apenas quatro empresas farmacêuticas brasileiras, suas conclusões não devem ser extrapoladas de forma indiscriminada.

\section{REFERENCIAS}

Andersson, S. (2000). The Internationalization of the Firm from an Entrepreneurial Perspective. International Studies Of Management \& Organization, 30(1), p. 63-92.

Associação Brasileira das Indústrias de Medicamentos Genéricos. (2017). Dados de Mercado. Recuperado em 27 maio, 2017, de http://www.progenericos.org.br/

Barreto, A. (2002). A Internacionalização da Firma Sob o Enfoque dos Custos de Transação. A Internacionalização das Empresas Brasileiras: Estudos de Gestão Internacional. Rio de Janeiro: Mauad, p. 41-59.

Bartlett, C. A., \& Ghoshal, S. (1992). Gerenciando Empresas no Exterior: A Solução Transnacional. São Paulo: Makron Books.

Banco Central Brasil. (2017). Boletim Focus - Relatório De Mercado-06/01/2017. Recuperado em 27 maio, 2017, de http://www.bcb.gov.br/pec/gci/port/readout/readout.asp

Banco Nacional Desenvolvimento Social. (2017). Classificação de Porte dos Clientes. Recuperado em 27 maio, 2017, de http://www.bndes.gov.br/wps/portal/site/home/financiamento/guia/quem-pode-ser-cliente/

Brito, C.; Lorga, S. (1999). Marketing Internacional. Porto: Sociedade Portuguesa de Inovação.

Buckley, P. (1983). New Theories of International Bussiness. London: George Allen, Cap.2, p.34-50.

Canals, J. (1994). La Internacionalización de la Empresa. Madrid: Mcgraw-Hill.

Casson, M.(1976). The Future of the Multinational Enterprise. London: Macmillina.

Cateora, P. R.; Graham, J. L (1996). International Marketing. New York: Mcgraw-Hill.

Dunning, J.H. (1998) The Eclectic Paradigm as an Evolve for Economic and Business Theories Of Mne's Activities. 
International Business Review, v. 9, p. 163-160.

Dyment, J. H (1987). Strategies and Management Controls for Global Corporations. The Journal Of Business Strategy, v.7, n.4, p.20-26, Spring.

Ferreira, D.; Cavalcanti Neto, S.; Gomes, J. S. (2014) Internacionalização de Empresas: Uma Análise Bibliométrica da Produção Científica dos Últimos Cinco Anos. Revista Magistro, 9(1), p. 1-23.

Gomes, R. D. P., Pimentel, V. P., Cardoso, M. L., \& Pieroni, J. P. (2014). O Novo Cenário de Concorrência na Indústria Farmacêutica Brasileira. Bndes Setorial, Rio de Janeiro, n. 39, p. 97-134.

Hemais, C. A.; Hilal, A. (2004) Os Desafios dos Mercados Externos: Teoria e Prática. Estudos da Copead/Ufrj. Rio De Janeiro: Mauad.v.1. 272.

Hymer, S. (1960). The International Operations of National Firms: A Study of Direct Foreign Investment. Cambridge, Ma.

Ims Heath. (2015). Empresa Especialista em Coletar e Analisar Dados do Setor Farmacêutico Com Presença Em Mais De 100 Países. Recuperado em 27 maio, 2017 de http:/www.imshealth.com.br/pt_br

Johanson, J.; Vahlne, J. (1977). The Uppsala Internationalization Process of The Firm: Knowledge Development and Increasing Foreign Market Commitments. Journal of International Business Studies, Basingstoke, v.8, p. 23-32.

Johanson, J.; Vahlne, J. (2009). The Uppsala Internationalization Process Model Revisited: from Liability of Foreignness To Liability Of Outsider Ship. Journal of International Business Studies, v. 40, n. 9, p. 14111431.

Johanson, J; Wiederscheim-Paul, F. (1975). The Internationalization Of The Firms: Four Swedish Cases. Journal Of Management Studies, Oxford, v.12, n.3, p. 305-322.

Laboratório Biolab. (2017) Descrição Do Laboratório Biolabfarma. recuperado em 27 maio.http://www. biolabfarma.com.br/

Laboratório Cristália. (2017) Descrição do Laboratório Cristália. Recuperado em 27 maio. http://www.2cristalia. com.br/\#\&panel1-1

Laboratório EMS. (2017) Descrição do Laboratório EMS. Recuperado em 27 maio. https://www.ems.com.br/

Laboratório Eurofarma. (2017) Descrição do Laboratório Eurofarma. Recuperado em 27 maio. http://www. eurofarma.com.br/pt/institucional/perfil.

Ministério da Indústria, Comércio Exterior e Serviços. (2017). Área de Imprensa. Recuperado em 27 maio, 2017, de http://www.mdic.gov.br/

Richardson, R. J., \& Peres, J. A. (1999). Pesquisa Social: Métodos e Técnicas. 3 Ed. São Paulo: Atlas.

Rodrigues, A, \& Gomes, J.S.(2003). O Sistema de Controle Gerencial de Uma Empresa de Serviços Internacionalizada: Caso Churrascaria Porcão. Viii Congresso Internacional de Costos, Uruguay.

Root, F. R. (1994). Entry Strategy for International Markets. San Francisco: Jossey-Bass.

Ruzzier, M.; Hisrich, R. D.; Antoncic, B. (2006). Sme Internationalization: Past, Present and Future. Journal of Small Business and Enterprise Development (Online). v. 13, n. 4, p. 476-497.

Sarathy, R; Terpstra, V. (1991). International Marketing. 5. Ed. Orlando: Dryden Press.

Serviço Brasileiro de Apoio às Micro e Pequenas Empresas. (2017). Critério de Classificação. Recuperado em 27 maio, 2017, de http:/www.sebrae.com.br/sebrae/portal\%20sebrae/ufs/sp/pesquisas/mpe_conceito_ empregados.pdf

Sindicato da Industria de Produtos Farmacêuticos No Estado de São Paulo. (2017). Indicadores Econômicos. Recuperado em 27 maio, 2017, de http://sindusfarma.org.br/cadastro/index.php/site/ap_indicadores

Souza, E.C.L; Fenili, R.R(2012). Internacionalização De Empresas: Perspectivas Teóricas E Agenda De Pesquisa. Revista De Ciências Da Administração, 2012. v. 14, n. 33, p. 103-118.

Vergara, S. C. (2016). Projetos e Relatórios de Pesquisa em Administração. 16. Ed. - São Paulo: Atlas.

Vernon, R. (1966). International Investment and International Trade In The Product Cycle. Quarterly Journal Of 
Economics, Cambridge, Mass., P.190-207.

Williamson, O. E. (1985). The Economic Institutions of Capitalism Firms Markets Relational Contracting. New York: The Free Press. 